\title{
A Case Study on Teachers' TPACK in 3D Dynamic Geometry Platform for Solid Geometry Learning
}

\author{
Zhangtao Xu \\ Central China Normal University, China \\ Shuhua An \\ California State University, Long Beach, USA \\ Mao Chen \\ Central China Normal University, China
}

The study reported the development of 15 pre-service teachers' TPACK in 3D dynamic geometry platform for solid geometry learning. The research selected a 3D dynamic geometry as an information technology tool and solid geometry as the content of the study. Teaching and learning geometry with the support of new technology is an urgent need in this technology rapid development era. Following the route of learning geometry, this study selected some lessons to investigate the level of the pre-service teachers' TPACK in $3 D$ dynamic geometry platform for solid geometry learning in China. The findings show that there was a declining trend in the four stages of integrating information technology with mathematics content. The possible reason lied in is that the pre-service teachers could not grasp the essence of mathematics content, and at the same time they did not have the habit to deal with mathematics content with the eye of technology. The study suggests that appropriate educational technology tools are important for the development of teachers' TPACK. The guided learning is an effective development modal for teachers. Lesson study with reflection is an important way to enhance teachers' TPCK.

Keywords: solid geometry, solid geometry intelligent education platform, the way of learning, the way of teaching

In recent decades, information technology gradually has become more accessible and it has been incorporated into everyday life, professional learning, occupational work, and entertainment. The National Council of Teachers of Mathematics (NCTM) (2000) held a viewpoint that technology is essential in teaching and learning mathematics and it has influences the mathematics taught. Technology can facilitate learners to visualize abstract ideas as well as organize and analyze data so that learners can focus on decision-making, reflection, reasoning, and problem-solving. With the 
launching of Technology Pedagogical Content Knowledge (TPACK) by Mishra and Koehler in 2006, numerous researchers agreed that the framework of TPACK has provided the knowledge base for the integration of technology and curriculum. When integrating technology into classroom, different subjects require different TPACK (Lai \& Lin, 2015). Wassong and Biehler (2010) provided a TPACK model for mathematics teachers in taking up the ideas from Mishra and Koehler (2006) and the ideas of mathematical knowledge for teaching (Ball, Thames, \& Phelps, 2008).

Niess et al. (2009) developed the mathematics teacher TPACK standards and development model. According to these standards and the development model, curriculum and assessment, learning, teaching, and access should be treated as a whole and the connection between the curriculum and assessment decision-making process should be highlighted. Algebra, plane geometry, analytic geometry, solid geometry, probability and statistics are the main components of secondary school mathematics. Mishra and Koehler (2006) had a similar view on TPCK that teachers need to know not just the subject they teach but also the manner in which the subject matter can be changed by the application of technology. For example, the subject matter of plane geometry and analytic geometry can be well taught by the geometric sketchpad. Graphing calculators have been instrumental in bringing statistical content to lower and lower grade levels (Chance, Ben-Zvi, Garfield, $\&$ Medina, 2007). For teaching solid geometry, models, manipulatives, and diagrams are widely used in classroom teaching in order to help students develop good conceptual images of three-dimensional geometric objects.

Recently, 3D dynamic software, like France Cabri3D, Math 3.0, and three-dimensional solid geometry of the Chinese $\mathrm{Z}+\mathrm{Z}$ intelligent education platform provides a potentially important new tool for developing visual education for solid geometry. Some studies conferred on the tremendous potential for using three-dimensional dynamic multimedia in teaching geometry (Yeh \& Nason, 2004; Erbas \& Yenmez, 2011). However, the above-mentioned 3D dynamic software has some shortcomings. For example, they cannot totally meet the need of teaching sometimes. To make some improvements Lin et al. (2014) developed a new 3D dynamic geometry platform-Pangu. Pangu comes into play an important effect on solid geometry classroom teaching. Various studies provided suggestions for using Pangu to help pre-service teachers develop their TPACK. Considering the importance of the ability of 3D space and difficulties to imagine spatially, and teachers' important role in student achievement, the purpose of this study was to assess the effects of using Pingeton on teachers' TPACK. Specifically, this study investigated which content of mathematics curriculum is in need of technology, examined the different information technology resources between two typical textbooks in China, and conducted teaching experiments to foster the development of the pre-service teachers' TPACK. The following research questions were examined in this study: 
1. Whether the existing technologies and education information resources can meet the need of teaching under the environment of information technology? This question can be decomposed into two sub-questions: (1) In the eyes of teachers, which content areas of education information technology should be used? (2) Do the textbooks provide efficient resources to support information technology going to curriculum and teaching?

2. With using the platform of Pangu, what are the changes in pre-service teachers' TPACK?

\section{Theoretical Frameworks}

\section{The Teaching of Solid Geometry}

School geometry. Solid geometry is an important part of high school curricula and has high practical value. Originally, geometry was a discipline to study shape, size and relative position relation of objects in the real world, and then it was developed to a study of the general spatial structure. School geometry is to study spatial objects, spatial relationships, mathematics transformation, and the axiom system that characterizes the relations among basic geometry elements. It generally refers to the Euclidean geometry; solid geometry is one of the important curricula of the school geometry. With many means can be used to study geometry, such as synthetic, analytical, transformational and vector methods, and so on, the teaching of solid geometry is an important and challenging task of high school mathematics curricula. As early as in 1901, J. Perry (1850-1920), a professor of the London Royal Society of Mechanics and Mathematics of England, argued that mathematics should come out of the bound of Euclid's framework. Perry suggested that more importance should be attend to experimental geometry, the application of geometry, and the actual measurement and approximate calculation. Perry also suggested that it is necessary to teach more three-dimensional geometry. Mammana and Villani (1998) echoed Peery's suggestions and pointed out that the geometry curriculum could not be confined to two-dimensional geometry and the starting point of geometry teaching must be a careful observation of realistic three-dimensional space. They further indicated that the importance paid to solid geometry should last up to high school levels and the focus should be put on the relations between two-dimensional and three-dimensional space. Since plane geometry abandons the reality and thus abstracts the relations of the two-dimensional space, while from the development of mathematics, the first formational geometry is experimental geometry, and then is classic Euclid's Elements, thus, Freudenthal (1973) pointed out that the way of the cultivation of spatial ability should go from the actual space directly to solid geometry. The physical space, which we live, is the source of solid geometry. The practical value of learning solid geometry is self-evident. 
Spatial thinking. Solid geometry has high educational value, too, which is expressed

by the education objectives of solid geometry. Usiskin (1987) divided geometry into four dimensions: (a) visualization, drawing, and construction; (b) the study of the space of material world; (c) as a tool to express the abstract mathematical concepts and relations; (d) as a representation to express formal mathematical system. In these four dimensions, the former three dimensions have a relation to spatial awareness. Thus, spatial awareness is an indispensable part of the geometry course. Van de Walle (2004) pointed out that the curriculum objective of geometry should be the development of geometry reasoning and the sense of space. Gardner (2006) argued that spatial ability is one of several relatively spontaneous human intelligences. Spatial thinking is essential for scientific thinking and it is always used to express and manipulate information in learning and problem-solving. The ability to recognize the similarity across different domains is obtained from many examples of spatial intelligence testimony. Hadamard (1949), a French mathematician, argued that the essence of higher level of mathematics thinking was spatial thinking. The high school curriculum standards of China (2000) indicated that the curriculum goal of solid geometry is to know the spatial graph, train and develop students' imagination, reasoning ability, communication ability with graphic language, and intuitive geometric ability. Solid geometry is a good carrier to develop spatial imagination ability, reasoning ability and geometry intuition ability. The learning of geometry will do help to know and understand human living space, explain and think about the physical environment, and provide tools for the study of mathematics and science topics.

Information technology in solid geometry. Information technology can play an important influence on the learning and teaching of solid geometry. Tall (1998) held the point that geometry belonged to specific visualization world; some geometry concepts had the natural basis. The formation of geometry concepts, in general, different from the formation of algebra concepts that go through from an operating process to a formed object, is abstracted from the relationship between spatial objects and their position locations. The learning of geometry concept should be based on students' intuitive experience. NCTM (2000) indicated that the well-designed activities by ways of physical modeling, painting and software can help students to learn shape, structure and nature of geometry, and can help students to infer geometric structure and learn geometric reasoning. The Japan curriculum standards (2008) pointed out that in the learning of space graphics, attention should be focused on the constituent elements of space graphics and understanding the positional relationship of the constituent elements of spatial graphics through observation, operation and experiment. It was a good way to discover mathematics facts by constructing spatial graphics or by observing. Viewing the composition of spatial graphics from the movement of plane 
graphics can enhance students' spatial imagination and intuitive ability. From the teaching practice, high school students generally find it difficult to learn solid geometry because student's' actual perception and mathematical abilities cannot be adapted to the mutation from two-dimensional space to three-dimensional space. The traditional approach adopts physical model and fine graph to improve students' spatial imagination, reasoning ability, and geometric intuitive ability. Although students live in a three-dimensional world with a lot of physical models and wall-maps used in classroom teaching, students' spatial imagination ability, reasoning ability, and geometry intuitive ability do not improve significantly. Mammana and Villani (1998) mentioned that to have the meaningful teaching process to the learners, any middle process from specific, intuitive geometry to abstract, deductive geometry cannot be skipped.

\section{Solid Geometry in Chinese Curriculum and Teaching Practice}

The solid geometry learning route given by China national curriculum standards is composed by four consecutive steps: intuitive perception, action confirmation, argumentation, measurement and calculation (Ministry of Education of the People's Republic of China, 2001). The learner should use this route to understand and explore the geometry and its nature.

Physical model is specific and also can be operated, but sometimes inconvenient or impossible to be used in the classroom teaching, which can be shown with some examples. The first example is Dandelin dual sphere model. It is not easy to exert its teaching effect due to the difficult task in realizing the process of using a plane to cut the cone. The traditional approach is to allow students to use their imagination to visualize the two spheres that are tangent both to a plane and to a cone that intersects the plane. However, the graphic is too complicated, and it is not easy to "image" it in mind. Therefore, this geometry content is not taught by teachers and learned by students, although this content is a part of Chinese textbooks.

Due to various reasons, the teaching of solid geometry does not effectively improve students' spatial imagination, reasoning capabilities, geometry intuitive ability, and spatial concepts. For example, Chinese textbooks use the vector method to deal with solid geometry (Chen, Li, \& Cheng, 2008). However, such an approach almost puts the intuitive and simple beauty of the geometry method to death. If using the vector method to deal with solid geometry, such an approach almost kills the intuitive and simple beauty of geometry. When using the vector method to deal with geometry problems, geometry is no longer geometry but becomes an applied field of algebraic methods. Drawing lessons from history can know the pros and cons of the teaching of solid geometry. For example, the new mathematics movement advocated abandoning Euclidean geometry, merging plane geometry and solid geometry, seeking new ways, such as transform or linear methods to establish the system of geometry. However, these reforms in 
geometry were not succeed. In the era of information technology, it is necessary to renew teaching method, highlight geometry intuition and the simplicity of beauty. Pangu 3D dynamic geometry system strives to display the beauty of images of solid geometry graphs and the beauty of logic reasoning of solid geometry system, and attain the course objectives of solid geometry through developing the spatial imagination ability and geometry intuition of students (Liu, Liu, \& Zhu, 2011).

\section{Mathematics Teachers' TPACK}

The framework of TPACK was born from PCK. Since Shulman (1965) introduced the notion of pedagogical content knowledge (PCK) as a knowledge basis for classroom teaching, PCK has been considered as a comprehensible way to represent subject matter knowledge and pedagogical content knowledge for teachers. The issue of PCK has received considerable critical attention with some insights into mathematics teachers' PCK.

Grossman (1990) identified four central components of PCK: (a) an overarching conception of what it means to teach a particular subject; (b) knowledge of instructional strategies and representations for teaching particular subject matter topics; (c) knowledge of curriculum and curriculum materials with learning subject matter. Another reconceptualization of teachers' PCK within mathematics education was mathematical knowledge for teaching (MKT) by Ball et al. (2008). MKT refers to the mathematical knowledge that is useful and directly used in mathematics classroom teaching. The concept MKT resulted from an attempt to refine and empirically validate PCK, and integrated content knowledge and PCK into a whole (Depaepe, Verschaffel, \& Kelchtermans, 2013). With the development of understanding of PCK, information technology began to have effect on teaching and learning. While access to technology without necessary knowledge of related curriculum materials did not encourage teachers to incorporate the technology in their classroom instruction (Kastberg \& Leatham, 2005).

Given the importance of technology in the 21 st century workplace, Mishra and Koehler (2006) proposed the seven constructs of the TPACK framework that integrated technology knowledge and PCK. The Association for Mathematics Teacher Educators (AMTE) advocated that all mathematics teachers and teacher candidates have opportunities to acquire the knowledge and experiences in order to incorporate technology in the context of teaching and learning mathematics (ATME, 2006). Niess (2005) adapted from Grossman's four components of PCK and framed a content-oriented TPACK. The TPACK consists of four identified central components: (a) an overarching conception about the purposes for incorporating technology in teaching mathematics; (b) knowledge of students' understanding, thinking, and learning of mathematics with technology; (c) knowledge of curriculum and curricular materials that integrate technology in learning and teaching mathematics; (d) knowledge of instructional strategies and representations for teaching and 
learning mathematics with technologies. Then the AMTE accorded this TPACK framework and proposed mathematics teacher TPACK standards and indictors. The TPACK standards include: (a) designing and developing digital-age learning environments and experiences; (b) teaching, learning and the mathematics curriculum; (c) assessment and evaluation; (d) productivity and professional practice. The TPACK framework provided content-specific ideas that address what students or teachers should know about using technology for learning mathematics (Niess, et al., 2009).

Scholars have interests in exploring how mathematics teachers' TPACK developed. Niess, Sadri, and Lee (2007) proposed a five-stage developmental model for TPACK: (a) recognizing (knowledge), where teachers are able to use technology and recognize the alignment of the technology with mathematics content yet do not integrate the technology in teaching and learning of mathematics; (b) accepting (Persuasion), where teachers form a favorable or unfavorable attitude toward teaching and learning mathematics with an appropriate technology; (c) adapting (decision), where teachers engage in activities that lead to a choice to adopt or reject teaching and learning mathematics with an appropriate technology; (d) exploring (implementation), where teachers actively integrate teaching and learning of mathematics with an appropriate technology; (e) advancing (confirmation), where teachers evaluate the results of the decision to integrate teaching and learning mathematics with an appropriate technology. The AMTE Technology Committee unpacked the teacher levels in thinking and understanding in the process of the development of TPACK. Four major themes further framed the Mathematics Teacher TPACK Development Model: Curriculum and Assessment, Learning, Teaching, and Access. Niess et al. (2009) expanded the Mathematics Teacher TPACK Development Model, providing detailed actions that teachers may experience and engage in while adapting technology in their teaching in order to enhance student learning.

Although there are many questions about the Mathematics Teacher TPACK Standards and the corresponding TPACK Development Model, the standards and model give us a lens to access the uses of technology in the mathematics classroom.

\section{Methodology}

This study is composed of two parts. The first part of the study employed a quantitative method to learn the need for classrooms for education information technology. The second part of the study employed a qualitative case study research design with the goal of characterizing subjects' use of Pangu 3D dynamic geometry system to support solid geometry instruction through analysis classroom observations, participant interviews, and artifacts such as lesson plan, student assignments, courseware presentations, and teaching reflections. 


\section{Participants and Procedures}

As the purpose of the present investigation was to characterize the authentic instruction needs for education information technology, 100 teachers from different high schools participated in the first part of the study. Participants ranged in teaching experience from one year to twenty years. The questionnaire item asked the participants to indicate that in their opinion, education information technologies should be used in which field, such as algebraic operation, plane geometry, analytic geometry, a graph of function, solid geometry, algorithm programming, and probability statistics. As is known, textbooks are an important resource for teaching. Two typical textbooks, published by People's Education Press and published by Hunan Education Press, were selected to be examined whether the education information resource from textbooks can meet the need of teaching.

For the second part of the study, fifteen pre-service teachers who have very strong interests in using education information technology in the teaching of solid geometry were selected as the participants. These fifteen pre-service teachers attended our teaching experiment course.

Usually, pre-service mathematics teachers in the university need to complete a sequence of mathematics education courses, such as mathematics teaching methods course, mathematics content analysis course, education information technology class with an emphasis on mathematics content and pedagogy, and microteaching course. Although all these pre-service teachers have attended the mathematics education information technology class, they could not use information technology tools in teaching solid geometry effectively. Referring to a general model of technology-enhanced inquiry instruction (Flick \& Bell, 2000), which provides a basis for teaching specific scientific content in a student-centered and engaging manner using appropriately selected technology, we designed a series of learning steps for the fifteen pre-service teachers below

To begin a lesson, teachers framed the whole purpose of this curriculum that was to combine the Pangu 3D dynamic geometry system with the content of solid geometry well and to introduce technology in the context of teaching solid geometry content. Then the pre-service teachers learned to operate basic functions of Pang 3D, such as construction, measurement, locus, trace, and so forth. When they had mastered the basic functions of Pang 3D, they could take advantage of the unique features of technology and put its usage into teaching. In this period, they began to think about the relationship between mathematics teaching and technology and made the content and views visual and accessible. Last, they had lessons with the Pangu 3D dynamic and developed understanding of the relationship between mathematics teaching and technology. For each of the teaching topics, the pre-service teachers wrote thoughtful reflections analyzing the effectiveness of their lessons, drawing on examples from their teaching experiences. 


\section{Data Collection}

For the first part of the study, the data about teachers' views on education information technology were collected by the questionnaire and the data about textbooks' education information resources were collected from the two typical textbooks. For the second part of the study, the pre-service teachers' instructional practices with technology were characterized through analysis of a wide variety of quality data. These data included formal and informal interviews, classroom observations, and additional teaching artifacts including lesson plans and teaching reflections. This variety of data sources allowed for a full characterization of each participant's technology-enhanced inquiry instruction; triangulation of these data sources increased the internal validity of the findings.

Observations. Classroom observations constituted the primary data source for characterizing participants' technology-enhanced solid geometry teaching. Each participant was observed for an entire 15-min lesson at least four times during the microteaching training. These observations were scheduled as a part of normal supervision of microteaching training; thus, lesson content, instructional model, and Paugu 3D platform represented the participants' typical solid geometry teaching. Field notes captured lesson content, interactions between teachers and students, use of technology, and solid geometry teaching within each observed lesson.

Lesson Plans and Artifacts. All lesson plans written and implemented throughout the entire microteaching training experience were collected. Additionally, participant-created supplemental resources, including PowerPoint presentations, courseware, and assessment documents were collected. Finally, reflective essays associated with the microteaching seminar provided additional insight into how and in what ways the pre-service teachers implemented solid geometry teaching supported by Pangu 3D platform throughout the semester. These artifacts served as valuable tools to validate statements made by participants during interviews.

Interviews. Throughout the microteaching, the researchers audited the pre-service teachers' classroom teaching. At the same time, the researchers conducted brief informal interviews with each participant to track their developing thoughts about technology integration. The interview questions focused on the pre-service teachers' thinking about when and how to integrate technology into their lessons, the extent to which technology influenced student engagement, and their students' understanding of curricular objectives.

\section{Data Analysis}

For the first part of the study, all the data were dealt with in 2010 Excel. For the second part of the study, the researchers followed an inductive data analysis process. Data sources included interview responses, observation notes, lesson plans, supplemental lesson plan materials, and teaching reflections. The analysis focused on identifying instances of using technology 
associated with the facilitation of whole learning of solid geometry. During this round of analysis, all data were independently analyzed, compared and reanalyzed by three coders in order to establish inter-coder agreement with regard to instances of using technology and learning solid geometry. Initial agreement was approximately $90 \%$ between coders. Differences were noted, discussed, and the data were revisited until consensus was achieved. Van Hiele's geometric thinking development levels (Clements \& Battista, 1992) were adopted to measure how pre-service teachers integrated information technology with geometry teaching. The levels of the pre-service teachers' TPACK were measured using the levels of geometric thinking development in visualization, analysis, abstraction, and deduction.

Referring to Van Hiele theory of geometric thought and the framework of the Van Hiele phases of learning (Van Hiele-Geldof, 1984), China national curriculum standards (2017) pointed out the teaching of solid geometry should focus on the essence of the solid geometry and lead students to experience the process of "intuitive perception--operation confirmation-argument and reasoning--measurement calculation" (p. 27) and by the process that makes students learn to explore and study geometry. The curriculum standards supposed this learning route could develop students' spatial imagination and intuitive geometry ability. Therefore, the data analysis of this study represented teachers' TPACK levels according to this learning route.

\section{Results}

\section{The Need from the Teaching and Learning}

The process of information technology used into education takes a detour. Extensive use of universal software, rather than use in-depth disciplinary information technology platforms, dampens the enthusiasm of teachers to use information technology into education.

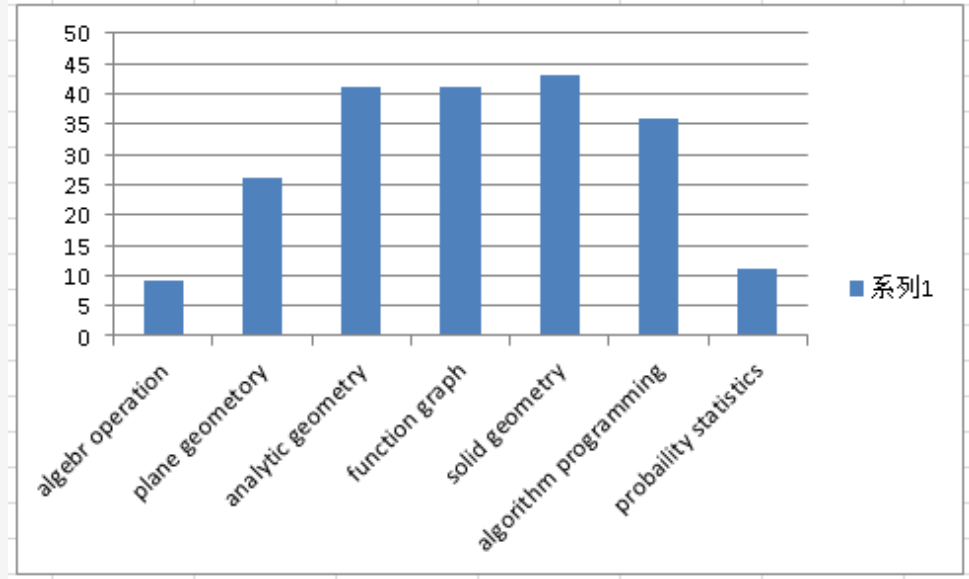

Figure 1. The information technology used in the view of teachers.

In order to know what kind of information technology platform is fit 
for the teaching and learning of solid geometry, this study used a survey. The survey item was "In your opinion, information technology can be used in what content?" The findings were shown in Figure 1.

The results in Figure 1 show that the most likely fields to use information were analytic geometry, function graph, solid geometry, which were related to graphics and images. In particular, in the field of solid geometry, teachers deem it necessary to use information technology. Although solid geometry adopts vector method, it is not an effective way to improve students' spatial capability, reasoning ability, spatial concepts and intuitive ability. It also reflects developing an intelligent education platform for solid geometry is an urgent requirement.

Some teachers said information technology could not only play the role of the electronic blackboard, only as an auxiliary teaching tool. The dynamic presentation of analytic geometry and function transformation can acquire good effectiveness. However, the results of the analysis of the textbooks show that China's current textbooks do not reflect this demand. Figure 2 can be seen that the information technology in both textbooks could not meet the needs of teaching of solid geometry.

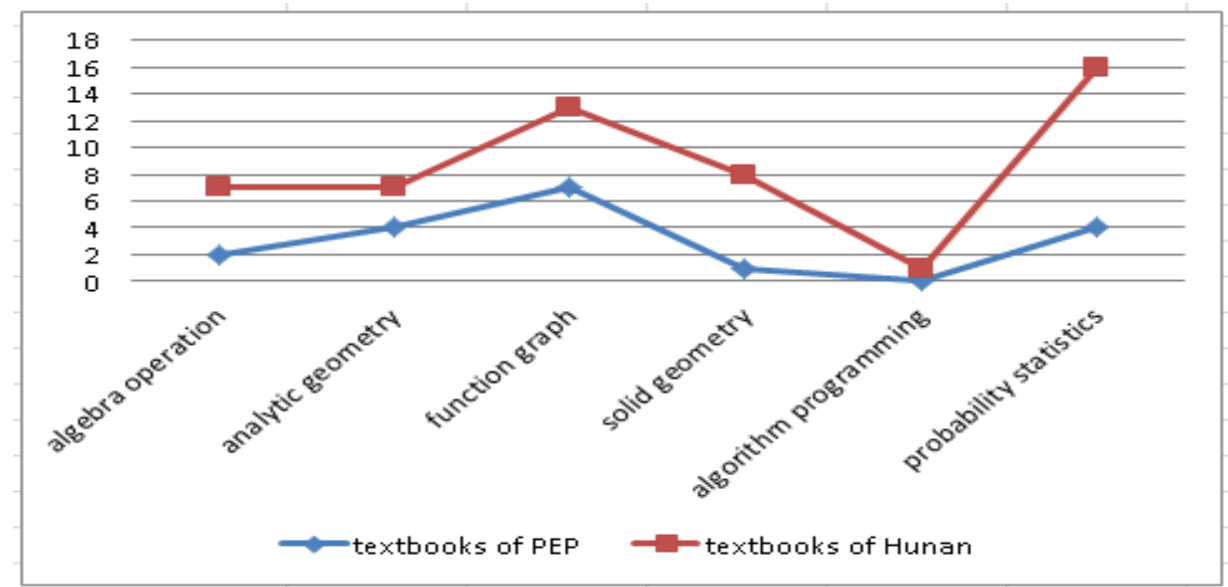

Figure 2. Information technology in two classical textbooks.

\section{Teachers' TPACK from Classroom Teaching}

Visual perception of space geometry and geometry Relationships.

When teachers use "chalk + blackboard" to draw graphs, students can flow the steps of drawing, and teachers can explain any spontaneous questions and make clarifications, which is advantage of using chalk and blackboard. However, drawing graphs on the blackboard would take up too much teaching time, only those teachers who received strict drawing training can make high-quality graphs. In this study, the fifteen pre-service teachers used geometry solid intelligent education platform to draw figures, easily expressed the geometry relationship between the various elements of geometry, and 
deepened the understanding of the nature of the geometry, which did not spend a lot of time. All participants made colorful solid geometry objects, such as the even regular tetrahedron, star anise, red five-point star, candied fruit strings with the pleasures of life, vivid fractal branches, and so on. The following were some drawings in Figures 3-7 from these participants:
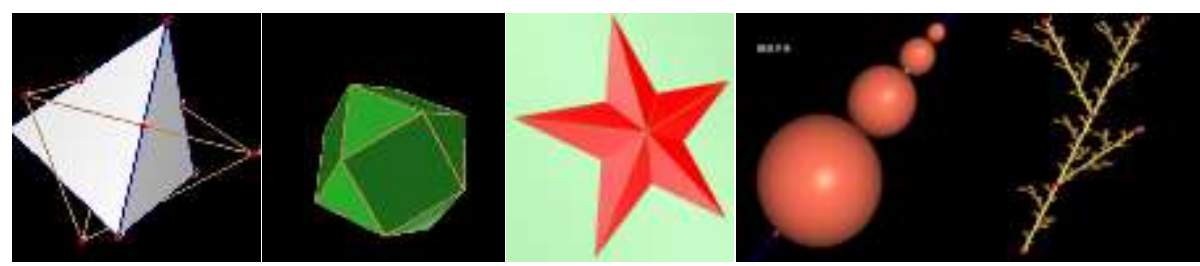

Figure 3-7. Tetrahedron, Star anise, Red star, A String of lollipops, \& Fractal branches.

The pre-service teachers used three-dimensional solid geometry intelligent education platform to draw many space graphs and operated the mouse to drag the geometry objects in different surface. Thus, students could perceive geometry objects in a different direction and developed their geometry intuition and spatial imagination. For example, one of the participants used a three-dimensional solid geometry education platform to simulate a natural phenomenon, which was beautiful and poetic in Figure 8.

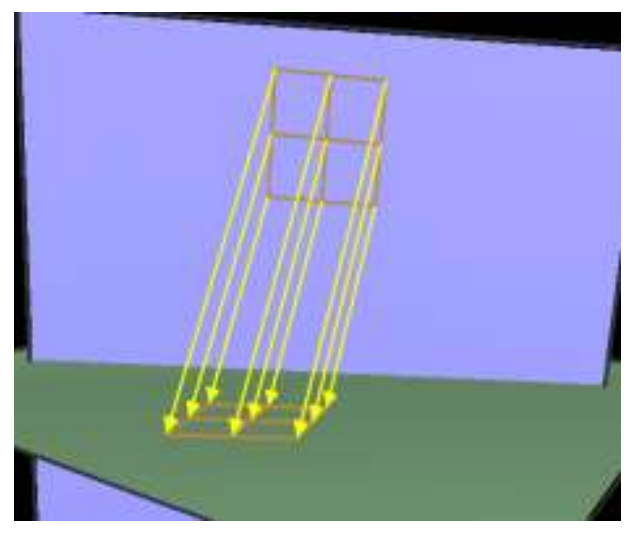

Figure 8. The projection of geometry object.

In the phase of information, all the pre-service teachers demonstrated TPACK to help students to reach the levels of visualization and analysis.

Freedom to operate and confirm geometry objects and geometry relationships. With the help of information technology-oriented to discipline, the way of mathematics learning may be promoted by carrying out experiments. Some classic classroom teaching segments were selected and presented to show how the pre-service teachers used information technology. 
Case 1: How to define the distance of the noncoplanar lines

A pre-service teacher, Mr. Xiao, provided a lesson of "The Distance of the noncoplanar lines." The researchers and other pre-service teachers observed this lesson. Mr. Xiao presented Figure 9 to students during the teaching.

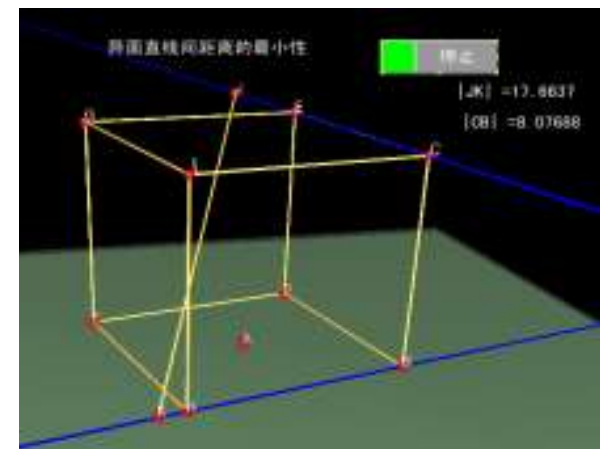

Figure 9. The minimum of the distance of the noncoplanar lines.

We have a depth interview with Mr. Xiao. He said, "When you click the green part of the bottom, you can see point J moves on the line EC, the length of JK constantly changes. There is a minimum. Then I stop the animation. I measure the angle between line KJ and line HB and the angle between line KJ and EG. There are two right angles. Therefore, I can know then minimum of the distance of the noncoplanar lines." Students cheered by the presentation. They all understood the reason why mathematicians define the distance of the noncoplanar lines in such a way.

All the pre-service teachers attended the depth interview. We put forward a question: After you listened to this lesson, can you design a microteaching to illustrate how to define the angle of the straight line and plane? A day later, all the pre-service teachers could answer this question satisfactorily. One of microteaching is shown with the following Figure 10.

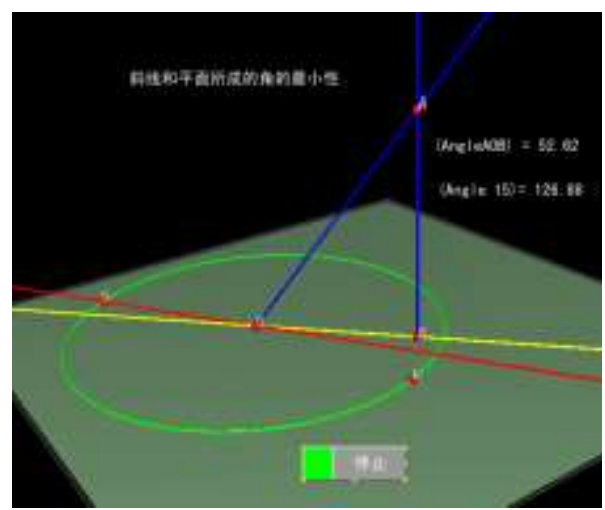

Figure 10. The minimum of the angle of the straight line and plane. 
In this phase, few pre-service teachers had TPACK to help students to reach the level of analysis. After guidance, all the pre-service teachers had TPACK to help students to reach the level of analysis.

Support measurement and calculation to change the way of learning. Measurement and calculation are important mathematical activities. According to legend, geometry originated from the measurement in the Nepalese river. Learning mathematics in experimental way is also a good idea. It would be better to reflect the nature of mathematics, the rational spirit of mathematics, the ideas and methods of mathematics, and the mathematics' pursue of simple and beauty through deeply studying the content of measurement and creating or re-creating the mathematics content of the mathematics measurement (Ding, Gao, Chen, \& Liu, 2006).

The results of this study show that all the pre-service teachers could use the module of measurement and calculation to teach. There are two typical teaching examples. The first example shows that with the support of information technology, a pre-service teacher simulated the natural phenomenon of "cutting hays in a guillotine" to illustrate the theorem of three perpendicular lines (see Figure 11). Figure 11 was the animation simulation, which shortened the psychological distance between students and the phenomenon of everyday life. Students were all absorbed by the presentation. One student said: "During the process of observation, I fully understand the physical experience, and know where the mathematical theorems are discovered."

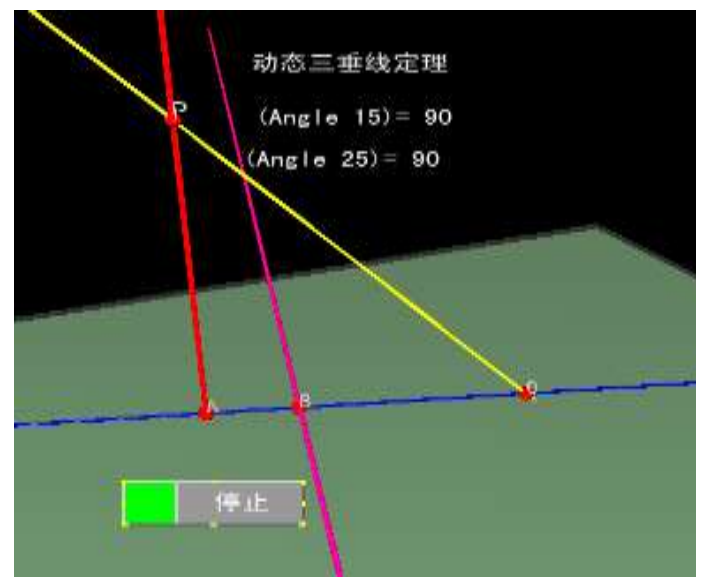

Figure 11. The theorem of three perpendicular lines

All the pre-service teachers were encouraged by the teaching of the theorem of three perpendicular lines. They said this integration of information technology and content went into the essence of mathematics and helped students understood well. They actively used the Pangu 3D platform in their teaching. A pre-service teacher, Ms. Zhang gave another example as shown in 
Figure12.

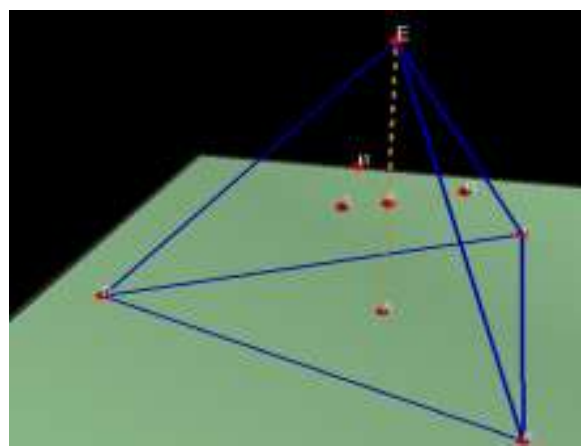

Figure 12. The distance of a point in the tetrahedral to the four sides is a fixed value.

Ms. Zhang used this courseware to carry out inquiring learning. All the students actively engaged in teacher-directed tasks. In this phase, all the pre-service teachers demonstrated TPACK to help students to reach the level of abstraction.

Support speculative argument to develop deductive reasoning ability. The ability of deductive reasoning is an important indicator of cognitive and intellectual development, but also is the indispensable ability to mathematics, science, and problem-solving (Siegler, 1991). The intuition of the geometry, the testability of falseness and truth by experience, and the predictability of the reasoning process make it the ideal material for the development of reasoning ability. Although the importance of deductive reasoning and speculative argument in geometry teaching has been generally accepted, the successful implementation of the school curriculum still has much difficulty. People are used to inductive thinking, but not used to the deductive reasoning that starts from the known conditions, concepts and theorems to a certain conclusion. Hoyles (1997) pointed out "it is difficult to form the ability of mathematical proof, as well as mathematics understanding, giving proof for middle school students" (p.27).

In this study, the researchers asked the pre-service teachers to select a topic and use the solid geometry intelligent education platform to find key to prove. To our surprise, no one could provide a courseware to expose the way of the thinking. After a teaching discussion meeting, the key hint to demonstration was brought home to the pre-service teachers. One of the pre-service teachers, Ms. Chen made an animation driving a line doing the translational motion in a plane, and then measuring the angle formed the line and another line that parallels the line in the plane. Ms. Chen said, "I get it. In any case, the line does not occur crooked, and then intersects with the plane, which is the key to prove this theorem by reduction ad absurdum."

In this phase, no pre-service teachers demonstrated TPACK to help 
students to reach the level of rigor. After guidance, few pre-service teachers demonstrated TPACK to help students to reach the level of rigor.

\section{Levels of the Pre-Service Teachers' TPACK}

According to the above-mentioned results, the levels of the pre-service teachers' TPACK can be summarized in Table 1.

Table 1. Levels of the Pre-service Teachers' TPACK

\begin{tabular}{lll}
\hline & Before guidance & After guidance \\
\hline Visualization & all & \\
Analysis & few & all \\
Abstraction & few & all \\
Deduction & $\ldots$ & few \\
\hline
\end{tabular}

It can be seen that it is a difficult point to develop the ability of deduction. Although

those shortcomings, with assistance of Pangu 3D platform, the pre-service teachers could do well in other aspects.

\section{Discussion and Implications}

The results of this study show that there was a declining trend in the four stages of integrating information technology with mathematics content. In the intuitive perception stage, all the pre-service teachers made vivid geometry works to discover the geometry relationship between the various elements of geometry, and deepen the understanding of the nature of the geometry, which did not spend a lot of time. In this stage, the pre-service teachers showed high levels of TPACK. They could use technology to the point. This is important for teaching. Although we live in a three-dimensional world, the types of geometry objects that we can see in everyday life are limited. In addition, these geometry objects are not scientific geometry objects. It is the teaching task that teachers can use appropriate tools as addressed in Common Core State Standards for Mathematical Practice (CCSSMP) (National Governors Association Center for Best Practices, Council of Chief State School Office, 2010) to make colorful solid geometry objects to help students, such as, the even regular tetrahedron, star anise, red five-point star, candied fruit string with the pleasures of life, lifelike fractal branches, which brings students the scientific enjoyment of arts and promotes creative in students' mathematics learning (Bickley-Green, 1995).

The pre-service teachers used the three-dimensional solid geometry intelligent education platform not only to show a lot of space graphics, but also to drag a geometry object and to let students observe the geometry object from different directions, and to make the project of the geometry object in 
different surfaces. Students can perceive geometry objects with different projections in different directions, which helps students develop their geometry intuition and spatial imagination (Cao, 2018). The pre-service teachers in this study used a three-dimensional solid geometry education platform to simulate some natural phenomena in classroom teaching. Such a teaching and learning process, by its nature, is reviewed as the development process of descriptive geometry by Gaspard Monge in the late eighteenth century. Acquiring some specific experiences can lay a certain foundation for students' thinking adapting to the requirements of the experimental geometry. In this stage, by making geometry works with the technology, the pre-service teachers used electric models to help students learn geometry and thus developed their TPACK.

In the second stage of analysis, not all the pre-service teachers could integrate technology with content well. Mathematics has the method of doing experiments, observation, induction, conjecture, validation, and refutation, and so on. With the help of information technology-oriented to discipline, the way of learning mathematics may be promoted by carrying out experiments such as using the $5 \mathrm{E}$ instructional model as addressed in the Mathematics Framework for California Public Schools (California Department of Education, 2015). Firstly, students engage in learning, and explore new mathematics knowledge and skills by carrying out experiential learning from doing experiments with mathematics; through explaining and elaborating, they gain accumulate rich, perceived, and internalized experience. Secondly, students enrich and extend the meaning of experience through evaluation so that the hand and brain can coordinate development. This is a new style of learning. Therefore, the pre-service teachers did not well prior to the guidance in this stage.

Any knowledge has two aspects. The first aspect of knowledge is formed or created through a learning process (Brix, 2014; Brix, 2017; Crossan et al., 2011); the other aspect of knowledge is the formed knowledge. In the process of the selection and organization of knowledge, knowledge is viewed as a definite object. However, when stressing the existence of knowledge in the curriculum, the formation process of the knowledge always be ignored. When knowledge is formed, mathematics knowledge is divided into concepts, theorems, rules, formulas and so on. During classroom teaching, it is necessary to restore the process of knowledge formation, restore the heat thinking in this process; restore its close connection with the people's emotions and ideological atmosphere of the community. In order to achieve this purpose, it is necessary to specially handle knowledge, deal with it in a dynamic and active way. The dynamic three-dimensional geometry intelligent education platform makes these ideas possible. In solid geometry, distance and angle are two important measures. For example, when defining the distance between the noncoplanar lines, the definition is reasonable. How do we verify that the distance has a minimum? How do we 
technically achieve this? When defining the angle of the straight line and plane, why using oblique line and projection to make the definition? Is the defined angle the only existence? How to verify it? Based on the content analysis, following a technical perspective, using the solid geometry intelligent education platform to make courseware will be able to answer these questions and explain the students' suspicions. The pre-service teachers in this study did not think these questions, and so they did not know where technology should be used. There are many reasons to explain this phenomenon. The lack of experience always is regarded as an important reason. However, after guidance, all the pre-service teachers could consider these problems and solve these problems. This seems that purposeful guidance can push forward the development of TPACK in the analysis stage.

In the third stage of abstraction, not all pre-service teachers knew how to use measurement to support learning and teaching. Experiment, calculation and reason are three basic ways of doing mathematics. Before the measurement, we have to consider why we should use measurement and measure, and think about what the law of the measured data contains. In addition, we should know the measurement is a kind of "confirmed" behavior in a scientific sense. There are measurement errors, and the outcome from measurement is not always accurate. Therefore, the conclusion from measurement may not be generalized because students need to attend precision in learning mathematics according to CCSSMP 6 (National Governors Association Center for Best Practices, Council of Chief State School Office, 2010). It needs to do further logical argument. The activity of measurement is an operating activity from explicit behavior, but it is related to how to use information technology and where to use it. The problem is related to the intrinsic cognitive activities, and it is necessary to give a reason for the action. Just using an information technology tool to measure, all the pre-service teachers can operate well. However, if the activity of measurement was used as a way to discover the essence of mathematics and help students to understand mathematics, not all the pre-service teachers can have high TPACK. This seems to signify that technology knowledge cannot convert TPACK automatically. Teachers should think about teaching and actively integrate information technology with content. Without the belief of information technology on teaching, teachers cannot have innovative teaching idea and behaviors. However, engaging teachers in using educational technology in the classroom and in developing their experiences can change teachers' educational beliefs according to Bruenjes (2002) and Burton (2003) as cited in Levin and Wadmany's study (2006).

If measurement can be looked as a new style of learning geometry by teachers, information technology can be effectively used in classroom teaching, and thus, their TPACK can develop.

In the fourth stage, the pre-service teachers were poor in TPACK. It is difficult for students to learn the formal proof in geometry (Weber, 2001). 
Weber proposed to use strategic knowledge - knowledge of how to choose with facts and theorems to apply. Poincare, a French mathematician, pointed out the theorem itself is not important, but how to find the theorem is important (Poincaré, 1910). Similarly, for a theorem, the key is not the process of proving, but to access the ideas. The ability of mathematical proof is not a natural, innate ability, is a man-made activity. There is no fixed pattern and routine to acquire the way of proof, from the perspective of cognitive psychology, insight and inspiration are necessary.

In terms of demonstration, it is most difficult to access to the way of thinking. Textbooks prove the judgment theorem of a line parallel to plane with reduction ad absurdum. The reduction ad absurdum is generally used to prove the proposition which cannot prove directly, or difficult to prove. In order to allow students to access to the idea of demonstration, using information technology makes animation, students can measure the angle of the two lines, which is zero in dynamic conditions, and they will come to realize that in either case, the line does not occur "bending", and then to intersect with the plane, which is the key to prove this theorem by contradiction. Subramanian (2005) did an investigation of high school geometry students proving and logical thinking abilities and the impact of dynamic geometry software on student performance. The results show a fairly significant effect on the tests of logical thinking. In this study, although the pre-service teachers mastered the formal proof, they could not use education technology as a tool to enlighten students and create opportunities for students to consider the logic relation between reason and effect. This probable reason lied in their not grasping the essence of mathematics. Therefore, they did not know how to represent this with the help of information technology. The Pangu 3D platform forced the pre-service teachers to think in this way and then their TPACK developed.

\section{Limitations and Future Directions}

This study examined the development of the pre-service teachers' TPACK. The results are limited to the pre-service teacher with a mandate for the Pangu 3D platform integration. The applicability of the framework and findings need to be validated in other primary schools, secondary schools as well as tertiary levels. These studies can be used to further examine how the pre-service teachers' TPACK develops under the environment of education information technology. The replication of the study in schools with varying degrees of education information technology is another way of understanding how the plat contexts may influence teachers' construction of TPACK.

The findings of this study suggest that the presence of external facilitators could influence the extent of teachers' TPACK construction. A future area of research would be examined if the external factors influence the development of TPACK to what extent. The applicability of the framework for 
teachers to make more effective plans for education information integration can be further examined. In future research, the actual implementation of lessons designed can be used to further understand the development of the pre-service teachers' TPACK with respect to the educational outcomes produced.

\section{Conclusion}

From the above analysis and discussion, some conclusions could be drawn. With the learning activity going further, the level of pre-service teachers' TPACK declines in this study. The probable reason lied in that the pre-service teachers could grasp the essence of mathematics content, and at the same time, they did not have the habit to deal with mathematics content with the eye of technology. Appropriate education technology tools are important for the development of teachers' TPACK. According to NCTM (2014), an excellent mathematics program should integrate the use of mathematical tools and technology as essential resources to help students learn mathematics with sense making of mathematical ideas, reasoning mathematically, and communicating their mathematical thinking. It is important to provide support to classroom teachers to use technology in mathematics classrooms. With the guidance, the level of pre-service teachers' TPACK was developed. It seemed that the guided learning is an effective development modal for enhancing teachers' TPACK. Math lesson study and reflection are important ways of enhancing teachers' TPACK too.

\section{References}

Association of Mathematics Teacher Educators. (2006). Preparing teachers to use technology to enhance the learning of mathematics. Retrieved from http://www.amte.net/

Ball, D. L., Thames, M. H., \& Phelps, G. (2008). Content knowledge for teaching: What makes it special? Journal of Teacher Education, 59(5), 389-407.

Chance, B., Ben-Zvi, D., Garfield, J., \& Medina, E. (2007). The role of technology in improving student learning of statistics. Technology Innovations in Statistics Education, 1(1):1-26.

Clements, D. H., \& Battista, M. T. (1992). Geometry and spatial reasoning. In D. A. Grouws (Eds.), Handbook of research on mathematics teaching and learning (pp. 420-464). New York: Macmillan.

Chen, X., Li, S., \& Cheng, H. (2008). Studying on the effect of solid geometry teaching with vector and synthetic methods. Journal of Mathematics Education, 17(3), 5557.

Depaepe, F., Verschaffel, L., \& Kelchtermans, G. (2013). Pedagogical content 
knowledge: A systematic review of the way in which the concept has pervaded mathematics educational research. Teaching and Teacher Education, 34(3):12-25.

Ding, E. S., Gao, C. M., Chen, H. B., \& Liu, C. M. (2006). Making efforts to compile a set of mathematics teaching materials in senior high schools with Chinese characteristics - The overall design thinking on the experimental teaching material of mathematics of curriculum standards in ordinary senior high schools of PEP Edition (Edition B). Curriculum, Teaching Material and Method, (03), 47-53.

Erbas, A. K., \& Yenmez, A. A. (2011). The effect of inquiry-based explorations in a dynamic geometry environment on sixth grade students' achievements in polygons. Computers \& Education, 57(4), 2462-2475.

Flick, L., \& Bell, R. (2000). Preparing tomorrow's science teachers to use technology: Guidelines for Science educators. Contemporary Issues in Technology and Teacher Education, 1(1), 39-60.

Freudenthal, H. (1973). Mathematics as an educational task. Dordrecht: D. Reidel Publishing Company.

Grossman, P. L. (1990). The making of a teacher: Teacher knowledge and teacher education. New York: Teachers College Press.

Hadamard, J. (1949). The psychology of invention in the mathematical field. New York: Dover.

Howard, G. (2010). Multiple intelligences. Retrieved from http://www.howardgardner.com/MI/mi.html

Hoyles, C. (1997). The curricular shaping of students' approaches to proof. For the Learning of Mathematics, 17, (1):7-16.

Kastberg, S., \& leatham, K. (2005). Research on graphing calculators at the secondary level: Implications for mathematics teacher education. Contemporary Issues in Technology and Teacher education, 5(1): 25-37.

Lai, T. L., \& Lin, H. F. (2015). Exploring mathematics teachers' perception of technological pedagogical content knowledge. Journal of Educational Media \& Library sciences, 52(1): 59-82.

Lin, Q.S., Fang, F., Yu, C. M., Zhang, Y. C., Hsiung, M.C., Salgo, I. S., .. Lee, P. W. (2014). Dynamic assessment of the changing geometry of the mitral apparatus in 3D could stratify abnormalities in functional mitral regurgitation and potentially guide therapy $[\mathrm{J}]$. International Journal of Cardiology, 176(3).

Liu, Z., Liu, G. H., \& Zhu, Z. (2011). Dragon 3D sketchpad - A solid geometry intelligent educational platform. 10.1109/PACCS.2011.5990093. Fhird pacific-Asia Conference on Circuits, Communications and System (PACCS).

Mammana, C., \& Villani, V. (1998). Perspectives on the teaching of geometry for the 21st century, An ICMI study. The Netherlands: Kluwer 
Academic Publishers.

Ministry of Education of the People's Republic of China (2001). Mathematics curriculum standards for general high schools (Experimental) [S]. Beijing: People's Education Press.

Mishra, P., \& Koehler, M. J. (2006). Technological pedagogical content knowledge: A framework for teacher knowledge. Teachers College Record, 108(6), 1017-1054.

National Council of Teachers of Mathematics. (2000). Principles and standards for school mathematics. Reston, VA: Author.

Niess, M. L. (2005). Preparing teachers to teach science and mathematics with technology: Developing a technology pedagogical content knowledge. Teaching and teacher education, 21(5): 509-523.

Niess, M. L., Ronau, R. N., Shafer, K. G., Driskell, S. O., Harper S. R., Johnston, C.,

Browning, C., Özgün-Koca, S. A., \& Kersaint, G. (2009). Mathematics teacher

TPACK standards and development model. Contemporary Issues in Technology and Teacher Education, 9(1), 4-24.

Niess, M. L., Sadri, P., \& Lee, K. (2007). Dynamic spreadsheets as learning technology tools: Developing teachers' technology pedagogical content knowledge (TPACK). Paper presented at the meeting of the American Educational Research Association Annual Conference, Chicago, IL.

Poincaré, H. (1910). Mathematical creation. The Monist, 20(3), 321-335.

Shulman, L. S. (1986). Those who understand: Knowledge growth in teaching. Educational Researcher, 15(2), 4-31.

Siegler, R. S. (1991). Children's thinking ( $2^{\text {nd }}$ ed.). Englewood Cliffs, NJ: Prentice-Hall.

Tall, D. (1998). Information technology and mathematics education: Enthusiasms, possibilities \& realities. In C. Alsina, J. M. Alvarez, M. Niss, A. Perez, L. Rico, \& A. Sfard (Eds.), Proceedings of the 8th International Congress on Mathematical Education (pp. 65-82). Seville: SAEM Thales.

The Japanese Ministry of Education. (2008). The learning guidance for primary and secondary schools [EB/OL]. Retrieved from http://www.mext.go.jp/a_menu/shotou/new-cs/youryou/chu/chu.pdf

Usiskin, Z. (1987). Resolving the continuing dilemmas in school geometry. .In M. M. Lindquist \& A. P. Shulte (Eds.). Learning and teaching geometry, k-12, 1987 Yearbook. Reston, VA: NCTM.

Van de Walle, J. A. (2004). Elementary and middle School mathematics: Teaching developmentally (5th ed.).White Plains, NY: Longman.

Van Hiele-Geldof, D. (1984). The Didactic of Geometry in the Lowest Class of Secondary School. In English Translation of Selected Writings of Dina Van Hiele-Geldof and Pierre M. Van Hiele, edited by D. Fuys, D. 
Geddes, and R. W. Tischler, 1959/1985. Brooklyn: Brooklyn College.

Wassong, T., \& Biehler, R. (2010). A model for teacher knowledge as a basis for online courses for professional development of statistics teachers. In C. Reading (Ed.), Data and context in statistics education: Towards an evidence-based society. Proceedings of the Eighth International Conference on Teaching of Statistics (pp. 41-46). Voorburg: IASE. Retrieved from http://icots.net/8/cd/pdfs/invited/ICOTS8_3C1_WASSONG.pdf

Weber, K. (2001). Student difficulty in constructing proofs: The need for strategic knowledge. Educational Studies in Mathematics, 48(1), 101-119.

Yeh, A., \& Nason, R. (2004). Knowledge building of 3D geometry concepts and processes within a Virtual Reality Learning Environment. In L. Cantoni \& C. McLoughlin (Eds.), Proceedings of World Conference on Educational Multimedia, Hypermedia and Telecommunications. Chesapeake, VA: AACE.

\section{Auhtors:}

Zhangtao Xu, Professor of Central China Normal University; P.R. China Shuhua An Professor of California State University, Long Beach, USA

Chen Mao, Corresponding Author, National Engineering Research Center of E-learning, Central China Normal University, P.R. China

Author's Note: This article is funded by China scholarship committee. However, the opinion does not represent the committee. 